\title{
Valve replacement for severe tricuspid regurgitation caused by Libman-Sacks endocarditis
}

\author{
JOSEPH LAUFER, MIRA FRAND, SIMCHA MILO* \\ From the Department of Paediatrics "C", and the Department of Thoracic and Cardiovascular Surgery, Chaim Sheba \\ Medical Centre, and The Sackler School of Medicine, Tel Hashomer, Israel
}

SUMMARY A rare case is reported of severe tricuspid regurgitation caused by Libman-Sacks endocarditis in a 9-year-old girl. The uncontrolled heart failure was successfully treated by tricuspid valve replacement.

Systemic lupus erythematosus is known to affect the heart in various ways. Though valvular involvement is common at necropsy (15 to $60 \%$ ), haemodynamically significant valvular disease is extremely unusual. When reported, valvular lesions usually involve the left side of the heart, causing mitral and aortic regurgitation. ${ }^{1-5}$ To the best of our knowledge the occurrence of severe tricuspid regurgitation in the course of systemic lupus erythematosus has not been reported. We describe such a patient who presented with severe congestive heart failure and who was successfully treated by tricuspid valve replacement.

\section{Case report}

A 9-year-old girl was admitted in February 1980 for investigation. At the age of 6 years she had begun to have febrile episodes associated with alopecia and polyarthritis. A diagnosis of rheumatic fever had been made and she had been treated with penicillin and corticosteroids for two years.

On examination she was a chronically ill and underdeveloped child. Multiple deformities of almost all joints were noted. There was no evidence of congestive heart failure. On palpation the heart was enlarged with a right ventricular heave. A blowing grade $3 / 6$ pansystolic murmur which become louder during inspiration was heard along the left sternal border. The second sound was normally split and a short mid-diastolic murmur was present. The electrocardiogram showed sinus rhythm, incomplete right bundle-branch block, and right ventricular hypertrophy. The chest $x$-ray film showed a moderately enlarged cardiac silhouette, with right atrial and right

^Present address: Department of Cardiothoracic Surgery, Lady Davis Carmel Hospital, Haifa 34362, Israel. ventricular enlargement. Echocardiography indicated right ventricular enlargement and paradoxical septal motion consistent with volume overload of the right ventricle. The tricuspid valve appeared somewhat thickened but no vegetations were seen. At cardiac catheterisation the following pressures were found: right atrium, $7 \mathrm{mmHg}$ with tall $\mathrm{V}$ waves; right ventricle, 30/0-7 mmHg; pulmonary artery, 22/10 mmHg; pulmonary wedge pressure, $10 \mathrm{mmHg}$. A right ventricular angiocardiogram showed massive tricuspid regurgitation, but no filling defects were seen in the right ventricular cavity. Laboratory investigations confirmed the presence of lupus erythematosus cells and a positive antinuclear antibody. Erythrocyte sedimentation rate was normal.

The diagnosis of systemic lupus erythematosus with cardiac involvement was established. The patient was treated with naproxen $500 \mathrm{mg}$ daily and responded well for the next two months.

In December 1980 she was readmitted, with sudden onset of severe congestive heart failure. She was apyrexial and the laboratory findings did not suggest reactivation of lupus erythematosus. Despite aggressive anticongestive therapy her condition rapidly deteriorated. Tricuspid valve replacement was advised and performed.

At operation, the pericardium was found to be very thick, oedematous, of moderately firm consistency, and adherent to the epicardium. The myocardium was grey and oedematous. The right ventricle contracted poorly. The right atrium was enlarged and its walls were thick with highly developed trabeculation. The tricuspid valve was smooth and without vegetations. Its annulus was dilated and its chordae elongated, allowing the valve to prolapse and blood to regurgitate during systole into the right atrium. The 


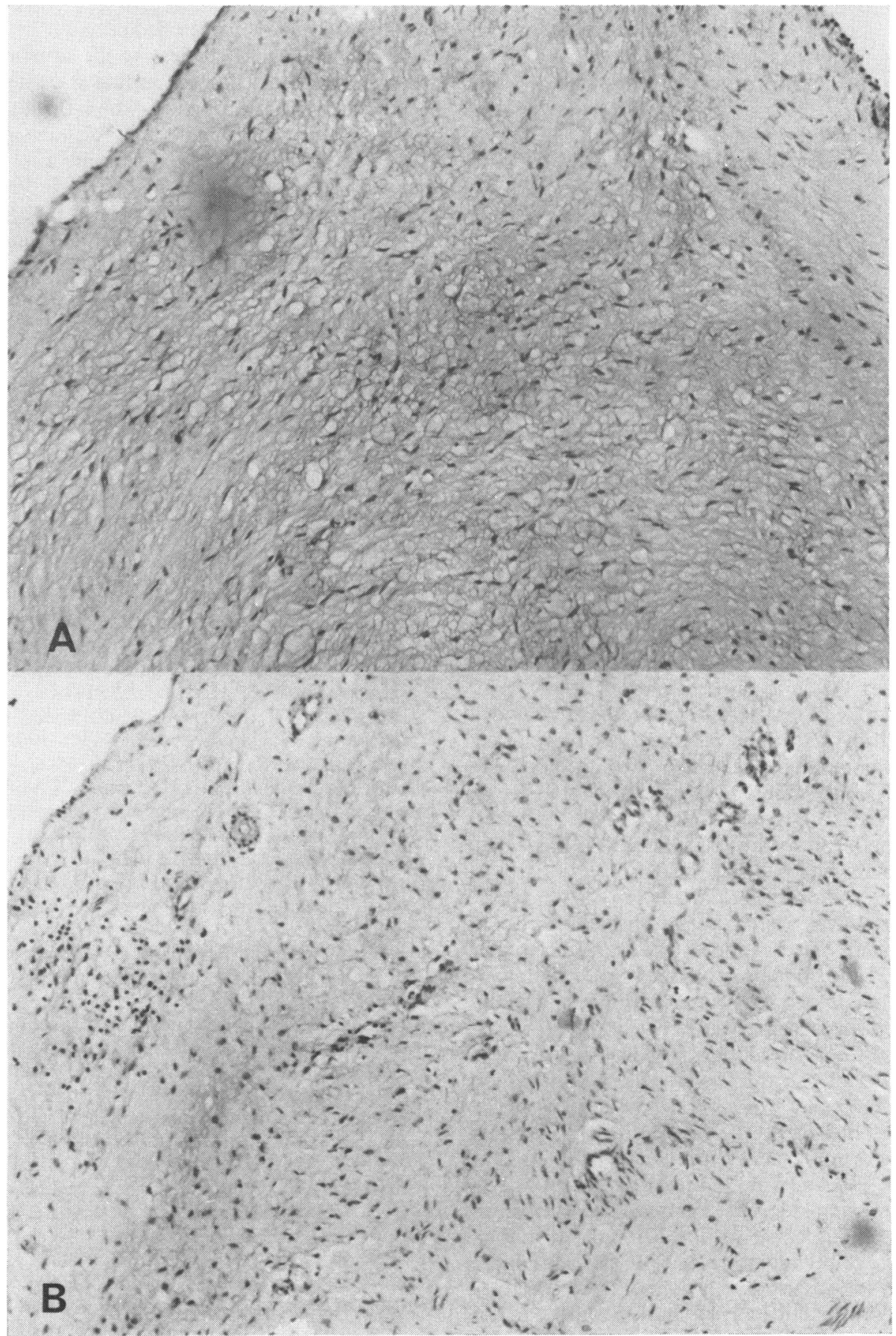

Fig. (A) Tricuspid valve cusps contain a large amount of mucopolysaccharides, best seen in Alcian blue stain. (B) There is no fibrosis, and a focus of macrophage cell infiltration is noticed at the left side of the figure (original magnification $\times 100$ ). 
subvalvular apparatus was normal. A size 27 mitral Björk-Shiley prosthesis was implanted.

Microscopical examination of the valve (Fig.) showed slight fibrosis with distinct increase in the mucopolysaccharide content of the matrix.

The postoperative course was uneventful and the patient was discharged four weeks after the operation without evidence of congestive heart failure.

\section{Discussion}

Systemic lupus erythematosus is a multisystem disease known to affect the heart in various ways. Pericarditis, ${ }^{6}$ myocarditis, ${ }^{7}$ endocarditis, ${ }^{7-10}$ coronary arteritis, 91112 and lesions of the conducting tissue $^{13}$ have been reported.

Libman-Sacks type endocarditis occurs in approximately half the patients with systemic lupus erythematosus. ${ }^{10}$ It may occur without murmurs and as it is rarely associated with clinically severe valvular dysfunction the disease usually remains unrecognised during life. The clinical picture of our patient was unusual in that she was known to have had a precordial murmur for three years and she developed severe congestive heart failure despite the otherwise benign course of her systemic disease. To our knowledge, severe tricuspid regurgitation requiring valve replacement in a patient suffering from systemic lupus erythematosus has not been previously described. Though Libman and Sacks ${ }^{13}$ stated that verrucae were most often found on the tricuspid valve, recent studies show that the mitral and aortic valves are more likely to be affected. ${ }^{710}$

It appears that the natural history of "cardiac" lupus erythematosus is changing, with the so-called healed Libman-Sacks endocarditis, an infrequent occurrence in the era before corticosteroids. The verrucae of Libman-Sacks type endocarditis are characteristically located on the ventricular mural endocardium, chordae tendineae, and papillary muscle, and usually do not distort the valve leaflets. Bulkley and Roberts, ${ }^{10}$ however, suggested that corticosteroids promoted healing of the verrucae, either as a direct effect of the drug, or as a result of longer survival of the patients. Though vital to the management of systemic lupus erythematosus, corticosteroids have an overall deleterious effect on the heart by increasing the incidence of valvular damage. ${ }^{10}$ In our patient the histology of the tricuspid valve was characterised by an increase in the mucopolysaccharide content of the valvular matrix. Similar findings were described by Bernhard et al. ${ }^{14}$ who considered this to be the result of corticosteroids.

Successful valve replacement has been reported in several adult patients with Libman-Sacks endocarditis of the aortic and mitral valves, ${ }^{1-5}{ }^{15}$ and the operation promptly relieved uncontrolled severe heart failure in our child. There is an analogy to the situation in children with active rheumatic carditis and severe failure because of valvar dysfunction, where the introduction of a prosthetic valve breaks the "vicious circle" and may be life saving, by allowing control to be gained over the failure and the active disease. ${ }^{16}$ Vaughton $e t$ $a l .,,^{15}$ however, have recently warned that active verrucous endocarditis may progress and cause severe dysfunction of the prosthetic valve.

\section{References}

1 Shulman HJ, Christian CL. Aortic insufficiency in systemic lupus erythematosus. Arthritis Rheum 1969; 12: $138-46$.

2 Oh WMC, Taylor RT, Olsen EGJ. Aortic regurgitation in systemic lupus erythematosus requiring aortic valve replacement. Br Heart $\mathcal{F}$ 1974; 36: 413-6.

3 Murray FT, Fuleihan DS, Cornwall CS, Pinals RS. Acute mitral regurgitation from ruptured chordae tendineae in systemic lupus erythematosus. $\mathcal{f}$ Rheumatol 1975; 2: 454-9.

4 Paget SA, Bulkley BH, Grauer LE, Seningen R. Mitral valve disease in systemic lupus erythematosus. A cause of severe congestive heart failure reversed by valve replacement. $A m \mathcal{F}$ Med 1975; 59: $134-9$.

5 Thandroyen FT, Matisonn RE, Weir EK. Severe aortic incompetence caused by systemic lupus erythematosus: a case report. S Afr Med F 1978; 54: 166-8.

6 Harvey AM, Shulman LE, Tumulty PA, Conley CL, Schoenrich EH. Systemic lupus erythematosus: review of the literature and clinical analysis of 138 cases. Medicine (Baltimore) 1954; 33: 291-437.

7 Brigden W, Bywaters EGL, Lessof MH, Ross IP. The heart in systemic lupus erythematosus. Br Heart $\mathcal{F} 1960$; 22: 1-16.

8 Kong TQ, Kellum RE, Haserick JR. Clinical diagnosis of cardiac involvement in systemic lupus erythematosus. Circulation 1962; 26: 7-11.

9 Hejtmancik MR, Wright JC, Quint R, Jennings FL. The cardiovascular manifestations of systemic lupus erythematosus. Am Heart f 1964; 68: 119-30.

10 Bulkley BH, Roberts WC. The heart in systemic lupus erythematosus and the changes induced in it by corticosteroid therapy. Am $\mathcal{F}$ Med 1975; 58: 243-64.

11 Meller J, Conde CA, Deppisch LM, Donoso E, Dack S. Myocardial infarction due to coronary atherosclerosis in $N$ three young adults with systemic lupus erythematosus. Am $\mathcal{F}$ Cardiol 1975; 35: 309-14.

12 Wray R, Iveson M. Complete heart block and systemic $\underset{\omega}{N}$ lupus erythematosus. Br Heart f 1975; 37: 982-3.

13 Libman E, Sacks B. A hitherto undescribed form of valvular and mural endocarditis. Arch Intern Med 1924; 33: 701-37.

14 Bernhard GG, Lange RL, Hensley GT. Aortic disease with valvular insufficiency as the principal manifestation of systemic lupus erythematosus. Ann Intern Med 1969; $\underset{\mathbb{D}}{\stackrel{\mathbb{D}}{ }}$ 71: 81-7.

15 Vaughton KC, Walter DR, Sturridge MF. Mitral valve $\stackrel{\mathbb{Q}}{\stackrel{\mathbb{Q}}{\circ}}$ 
replacement for mitral stenosis caused by Libman-Sacks endocarditis. Br Hean f 1979; 41: 730-3.

16 Lewis BS, Geft IL, Milo S, Gotsman MS. Echocardiography and valve replacement in the critically ill patient with acute rheumatic carditis. Ann Thorac Surg 1979; 27:
529-35.

Requests for reprints to Dr Simcha Milo, Department of Cardiothoracic Surgery, Lady Davis Carmel Hospital, 7 Michal Street, Haifa 34362, Israel. 